\title{
Analysis of Russia's Regional Socio-Economic Situation Indicators
}

\section{Galina V. Backusheva}

\author{
Financial University under the Government of the Russian Federation, (Financial University), Moscow, Russia
}

\section{Galina A. Paymakova}

Mari state university, Yoshkar-Ola, Russia

Email: paymakova@mail.ru

\section{Doi:10.5901/mjss.2015.v6n3s7p47}

\begin{abstract}
The article analyzes the socio-economic indicators that influence the future gross regional product growth. The mutual influence of the gross regional product (GRP) and socio-economic development indicators reflects the regional economic development perspective. The goal of the article is to show the theoretical analysis possibilities for practical use in regional planning and forecasting. The analysis of certain exogenous variables that affect the gross regional product is made. It is found that the preliminary indicator analysis may determine the most significant development factors for the region. The econometric models that quantify the contribution of the significant factors in the formation of the two most important regional socioeconomic situation indicators - gross regional product and gross regional product per capita - are constructed. This analysis can be useful to flesh out the government support programs for the regions and determine the possible dynamics of GRP.
\end{abstract}

Keywords: Gross regional product, socio-economic indicators, regional development, econometric model

\section{Introduction}

Lots of the world countries are spatially divided into the separate regions, for example, the USA are divided into the states, Germany - into the lands, the Russian Federation - into the subjects (regions). National legislation of the different countries provides the regions with the different political and economic powers. However, the vital activity of any country supposes the common economic space. Consequently, the federal structure countries have to pursue an active federal policy aimed at eliminating regional disparities, strengthening economic and political integrity of the country. The socioeconomic indicators, measured in each region, may indicate existence of disparities.

Regions of the Russian Federation are self-directed subjects. The Government of the Russian Federation draws attention to the significant regional development differences. The federal target program "The reduction of the differences in the socio-economic development of the Russian Federation regions (2002-2010 and up to 2014)" expired in 2015. This program used for about ten targets. By the end of the period it was planned to reduce the gap between the developed and lagging regions 2 times, reduce inter-regional differences in per capita income by 3 times, and reduce the proportion of people living below the poverty line by 25 percent.

The studies of the Volga Federal District showed the regional development disparities reduction among the regions included in the Volga Federal District over the period from 2005 to 2012, but the territorial balance of their socio-economic development is missing. The gap between the strong and the weak region is significant. The gross regional product per capita of the Republic of Tatarstan exceeds the level of GRP in the Volga Federal District by 41.9\%, while the GRP per capita of the Republic of Mari El is behind that level by 35.9\% (Backusheva \& Paymakova,2015).

Currently there is no unified system of indicators assessing the socio-economic development. The scientific literature analysis showed no common approach. The regional socio-economic development researchers base upon various indicators. So Borodkin F.M. and Ayvazyan S.A. consider the macroeconomic indicators as the social indicators (Borodkin \& Ayvazyan, 2012). Skotarenko O.V. classified the different points of view on the composition of the indicators (Skotarenko, 2013). Academician S.J. Glazyev and professor V.V. Lokosov suggested using not the absolute values but the ultimate indicator values, including the Gini coefficient, unemployment rate, crime rate and others. The ultimate level is the level that goes beyond the boundaries of economic security, when the system enters the area of economic, demographic and other risks (Glazyev \& Lokosov, 2012). 


\section{Methods}

Two key indicators that characterize the socio-economic situation of the regions are singled out in this study - gross regional product (GRP) and GRP per capita. This option allows to correlate the production of gross regional product with the spatial regional economy management. The corresponding Federal Law N 172-FZ "About the strategic planning in the Russian Federation" was adopted 28.6.2014. (hereinafter - the Law). Article 20 of the Law is aimed at strategic planning of social and economic development of the Russian Federation, it involves the selection of regional development goals and objectives. Article 21 of the Law aims at making strategic decisions about the state programs designing for the macro-regions development.

Strategic planning of the region functioning, first of all, means the social development management in all its forms: the production of social products taking account of the resource potential, the improving of the people's vital activity conditions, the formation of the social and cultural environment of the region. For a long time in the Russian science and practice the evaluation of the regional development was carried out only from the perspective of its contribution to the gross domestic product of the state. Currently, much more attention is paid to the population life quality. It is scientifically proved that these two aspects of life in the region are interlinked and mutually enrich each other. It is no coincidence that a lot of attention is paid the socio-economic indicators.

The strategic planning process is based on the preliminary analysis of the socio-economic development of the regions. The regional socio-economic situation analysis is multifactorial. The influence of the different indicators on the selected resultant factors was studied with the help of econometric methods. The algorithm of analysis can be represented by the following steps: defining the purpose of the analysis; selecting the level of examination (federal district, region); defining the meaningful indicators; choosing the model specification; gathering statistical information; estimating the model's parameters; verifying the model.

The socio-economic development indicator analysis is a complex procedure that requires the large amount of information.

The study is based on the database generated by the International Centre for the Study of Institutions and Development of the National Research University Higher School of Economics: iims.hse.ru/csid/databases, supplemented by the gross regional product (GRP) and GRP per capita data obtained from the Russian Federation Federal State Statistic Service: www.gks.ru.

The GRP per capita across all the subjects of the Russian Federation in 2012 is selected as the endogenous variable of the first model, the endogenous variable of the second model is respectively GRP. The set of exogenous variables consists of 36 variables of researcher's interest in terms of detection the influence on the resulting variable. There are both quite conventional factors among these variables as: fixed asset investment, the unemployment rate, the average monthly wage - and quite unconventional factors: the distance from the regional capital to Moscow, the number of crimes committed in the economic sphere, the number of created / liquidated legal entities.

The original database and the set of the regions were revised - first of all, those regions which data was incomplete were removed, and secondly, the regions which had the value of the resulting variable that could be considered as an outlier were either removed. The final sample contains cross-sectional data on 63 subjects of the Russian Federation in 2012: the learning sample includes data on 62 subjects, data for the Republic of Mordovia are separated as the controlling sample to check the adequacy of the constructed models.

It is known that even the simplest models sometimes allow to obtain interesting and useful results, therefore the linear regression model is selected as the model specification. The factor selection for the first model was carried out with the help of the successive elimination and the correlation coefficient matrix analysis. The factor selection for the second model was carried out in various ways - by the successive elimination, by the combination of the correlation coefficient matrix analysis and the successive addition method. The necessary calculations were executed in Microsoft Excel.

\section{Results \& Discussion}

The analysis of the 36 initial factors revealed the 8 significant amongst them:

$x_{1}$ - the distance from the regional capital to Moscow, $\mathrm{km}$.,

$x_{2}$ - the average nominal payroll wages, rub.,

$x_{3}$ - the share of money income by quintiles: the last $20 \%$ group with the highest incomes,

$x_{4}$ - Gini coefficient, 
$x_{5}$ - the labor force participation rate (economic activity rate), $\%$,

$x_{6}$ - the number of economic crimes,

$x_{7}$ - investments in fixed capital, in current prices, million rubles, all types of enterprises,

$x_{8}$ - accumulated foreign direct investment at the beginning of the year, thousand USD, total.

However, the free term estimate of the equation is negative, that is probably not compatible with the economic sense of the endogenous variable. To solve this problem, the scatter plot was built, the diagram gave the reason to assume that the regions can be grouped depending on the value of the gross regional product. For the further study all the regions were divided into two parts - with GDP per capita of up to 250 thousand. rub. and over 250 thousand. rub. The first group consists of 36 subjects, including the Altai Territory, Republic of Kalmykia, Dagestan Republic, the Republic of Mari El, Kirov and Penza regions. The second group includes 26 regions with the high GDP per capita, among them the Republic of Tatarstan, Nizhny Novgorod region, Primorsky Krai, the Republic of Bashkortostan. As a result, the dummy variable was included into the equation, it takes the value 0 for the regions of the first category and takes the value 1 for the regions of the second category. This variable appeared to be significant at the $5 \%$ significance level.

The study of the selected in the first step 8 factors shows that the simultaneous introduction of some variables in the equation is undesirable due to the emerging model multicollinearity, in particular, the correlation coefficient between

$x_{3} x_{4}$ - the share of money income by quintiles and Gini coefficient - is 0.9996 . As a result, it was decided to retain only the Gini coefficient. However, this variable was either excluded from the further analysis because it is recognized as quasi-constant because the coefficient $v=\frac{S}{\bar{x}}$, where $S$ stands for the standard deviation of the Gini coefficient and $\bar{x}$. for the average value equals 0.04 .

To reduce the multicollinearity in the model one more regressor $-x_{8}$ - accumulated foreign direct investment at the beginning of the year - was either removed since the partial correlation of this factor with GRP per capita equals 0.05 and therefore it may be considered insignificant.

The labor force participation rate (economic activity rate) - $x_{5}$ - has been replaced by the more traditional factor the unemployment rate. Thus, the final model is represented as follows::

$$
\begin{aligned}
& y=\underset{(32843,49)}{62853,86}-\underset{(2,60)}{4,79 \cdot} x_{1}+\underset{(1,69)}{9,20} \cdot x_{2}-\underset{(3,21)}{6,00} \cdot x_{3}+\underset{(0,04)}{0,08} \cdot x_{4}-\underset{(1920,59)}{5332,28} \cdot x_{5}+ \\
& +\underset{(11492,16)}{58101,32 \cdot d+\underset{(29915,59)}{\varepsilon}},
\end{aligned}
$$

где ${ }^{x_{1}}$ - the distance from the regional capital to Moscow, km.,

$x_{2}$ - the average nominal payroll wages, rub.,

$x_{3}$ - the number of economic crimes,

$x_{4}$ - investments in fixed capital, in current prices, million rubles, all types of enterprises,

$x_{5}$ - the unemployment rate (International Labour Organization methodology), \%,

$d=\left\{\begin{array}{l}0,- \text { if } \quad y<250000 \text { rub. } \\ 1-\text { if } \quad y \geq 250000 \text { rub. }\end{array}\right.$

Some factors can be formally recognized as significant by only $7 \%$ level of significance, but it is the result of the partial multicollinearity presence in the model. All the factors of the model are useful and must not be removed since the removal of any of them leads to a decrease in the value of the adjusted coefficient of determination.

The model successfully passes all the formal tests (at the $5 \%$ level of significance;):

$J B=1,32<\chi_{\text {crit }}^{2}=5,99$ - the Jarque-Bera test, the hypothesis that the errors are normally distributed is accepted;

$R^{2}=0,83, F$-significance $=1,48 \cdot 10^{-19}$ - the null hypothesis that all of the slope coefficients, excluding the constant, in a regression are zero is rejected,

Mean Absolute Percentage Error (MAPE) $=9,79 \%$ - the model has sufficiently high precision;

RESET :F $=0,71<F_{\text {crit }}=3,17$ - Ramsey's Regression Error Specification Test, the linear regression model specification may be accepted as correct; 
$W=12,37<\chi_{\text {crit }}^{2}=19,68$ - White test, the null hypothesis is accepted so the residual variance may be accepted as constant and that means homoscedasticity;

$B G=0,64<\chi_{\text {crit }}^{2}=5,99$ - Breusch-Godfrey test, the null hypothesis that there is no serial correlation of order 2 is accepted.

The model is verified on data for the Republic of Mordovia. The point prediction for the Republic of Mordovia is 170 484.57 rub. while the actual value equals 163399 rub. The model verification by constructing confidence interval shows its adequacy. However, it should be noted that the standard error of the model is sufficiently large, so there is a need of searching for the new factors to include into the model.

As it is shown above, the model is recognized suitable for the analysis and forecasting and, therefore, it would be reasonable to analyze the coefficients estimates:

- If the distance from the regional capital to Moscow increases by $1 \mathrm{~km}$., GRP per capita falls, on average, by 4.79 rubles. This fact can be explained by disparities linked to the placement of financial resources, most of which are concentrated in Moscow.

- If the average nominal payroll wages increase by 1 ruble, GRP per capita grows, on average, by 9.20 rubles. This means that the production volume can be stimulated by the wage increase. The wage generates the labor motivation. The wages polarization by the regions of the country causes the migration of skilled labor force to the developed regions, where the labor efficiency improves. The human potential is reducing in the regions with the low wages, the labor efficiency (productivity) falls.

- If the number of economic crimes increases by 1 unit, GRP per capita falls, on average, by 6.00 rubles. This fact clearly demonstrates the benefit of the measures taken by the state to fight corruption.

- If the volume of investments in fixed capital increases by $1 \mathrm{mln}$. rubles., GRP per capita grows, on average, by 0.08 rubles. The volume of investments in fixed capital is traditionally considered as one of the main factors that increases the production volumes. The positive sign of the coefficient estimate confirms this pattern, but the value of the coefficient estimate is small, it raises questions about the effectiveness of the investments. The search for solution of the import substitution problem requires the further analysis of the investments structure in the context of ownership patterns and economic sectors.

- If the unemployment rate increases by 1\%, GRP per capita falls, on average, by 5332.28 rubles. Thus, the fight against unemployment remains an urgent task for the regional management authorities as it has a huge effect on the volume of GRP per capita. The problem is not only in cyclical unemployment, which increases the marginal segments of the population, the structural unemployment is slowly overcome.

The second linear regression model with GRP, mln. rub. as the endogenous variable was built.

The most successful model is calculated by the successive elimination method:

$$
y=\underset{(77059,09)}{415902,61-18,42 \cdot x_{1}}+\underset{(6,34)}{20,26} \cdot x_{2}+\underset{(0,02)}{0,16} \cdot x_{3}+\underset{(0,69)}{2,80} \cdot x_{4}+\underset{(0,16)}{0,55} \cdot x_{5}+\underset{(84441,88)}{\varepsilon}, w^{\prime} x_{1} \text { - the distance from }
$$

a regional capital to Moscow by motor road, kilometers,

$x_{2}$ - the average nominal payroll wages, rub.,

$x_{3}$ - residential population, yearly average,

$x_{4}$ - total number of enterprises at the end of the year,

$x_{5}$ - investments in fixed capital, in current prices, million rubles, all types of enterprises.

The formal testresults (at the $5 \%$ level of significance;):

$J B=3,94<\chi_{\text {crit }}^{2}=5,99$ - the hypothesis that the errors are normally distributed is accepted;

$R^{2}=0,96, F-$ significance $=7,57 \cdot 10^{-39}$ the null hypothesis that all of the slope coefficients, excluding the constant, in a regression are zero is rejected;

$R E S E T: F=2,02<F_{\text {crit }}=3,17$ - the linear regression model specification may be accepted as correct;

$B G=0,04<\chi_{\text {crit }}^{2}=5,99$ - the null hypothesis that there is no serial correlation of order 2 is accepted;

$W=25,86>\chi_{\text {crit }}^{2}=18,31$ - the null hypothesis is rejected so the residual variance may not be accepted as constant and that means heteroskedasticity, this may indicate the heterogeneity of the objects in the sample;

MAPE $=22,68 \%$ - the accuracy of the model is quite low.

Thus, the model that describes the GRP needs to be improved, there is probably a need of subdividing the regions 
into several parts in terms of GRP. The attention to the negative value of the free term must be also paid, although the constant value is often not interpreted, nevertheless, the negative value of the constant, in our opinion, is economically unjustified in this model.

Also it can be seen that the estimated coefficient that reflects the contribution of investment has appeared to be small again. This, however, should not lead to the conclusion of the low investment importance in the formation of the gross regional product. Correlation analysis shows that this factor has one of the highest values of the correlation coefficient with the GRP.

\section{Conclusion}

Econometric analysis confirmed that the whole set of related indicators describes the socio-economic situation in the region. Creating a system of priority indicators for the analysis is the most important task for the regional authorities, the solution of this task will allow to make the most reasoned decisions and develop the region.

In this article two main indicators - GRP per capita and total GRP - were singled out.

The conducted analysis let us draw a conclusion about the importance of the following factors in the development of the region:

The distance from the regional capital to Moscow, the average nominal payroll wages, stratification of society by income (Gini coefficient), residential population, yearly average, total number of enterprises at the end of the year, the labor force participation rate (economic activity rate), the unemployment rate (International Labour Organization methodology), the number of economic crimes, investments in fixed capital, in current prices, accumulated foreign direct investment at the beginning of the year.

These factors correspond to the potential of the Russian State Statistics. The proposed model describes the possibility and expediency of their use in the decision-making at the federal and regional levels in order to balance the regional differences and disproportions.

The further studies may be related both to the search for additional significant factors and to the search for a more complex specification of a model.

\section{References}

Federal law of the Russian Federation "About the strategic planning in the Russian Federation" (2014). From http://www.rg.ru/2014/07/ 03/strategia-dok.html

The Federal Target Program "Reducing the differences in socio-economic development of regions of the Russian Federation (20022010 years, and up to 2015)" (amended 20 October 2006) //http://docs.cntd.ru/documtyt/901798969)

Backusheva, G.V., Paymakova, G. A. (2015). Regional growth as management policy indicator. The Fifth International Conference on Economic Sciences. Proceedings of the Conference Vienna, OR: «East West» Association for Advanced Studies and Higher Education $\mathrm{GmbH}$, Vienna.

Borodkin, F.M., Ayvazyan, S.A. (2012). Social Indicators: A textbook for university students. Moscow. UNITY-DANA, 2012. 607p.

Glazyev, S.Y., \& Lokosov V.V. (2012) Estimates of the maximum values of the indicators of critical state of Russian society and their use in the management of socio-economic development. Journal Bulletin of the Russian Academy of Sciences. T. 82; № 7: 587 604.

Skotarenko, O.V. (2013). The Russian experience of the socio-economic development of the region. Journal Basic Researching; № 1-3; 823-829. 
